\title{
Outpatient Follow-Up Visit after Hospital Discharge Lowers Risk of Rehospitalization in Patients with Schizophrenia: A Nationwide Population-Based Study
}

\author{
Seung Yup Lee ${ }^{1 *}$, Kyoung Hoon Kim²*, Tae Kim¹, Sun Min Kim², Jong-Woo Kim¹, \\ Changsu Han ${ }^{3}$, Ji Young Song ${ }^{1}$, and Jong-Woo Paik ${ }^{1 凶}$ \\ ${ }^{1}$ Department of Neuropsychiatry, College of Medicine, Kyung Hee University, Seoul, Republic of Korea \\ ${ }^{2}$ Health Insurance Review \& Assessment Service, Seoul, Republic of Korea \\ ${ }^{3}$ Department of Psychiatry, College of Medicine, Korea University, Seoul, Republic of Korea
}

Objective Non-adherence to medication is a recognized problem in psychiatric patients and may be one of the most challenging aspects of treatment for patients with schizophrenia. Failure of follow-up care after discharge greatly increases non-adherence to prescribed medications, relapse and rehospitalization. However, it is still unknown whether and how much outpatient follow-up visits can mitigate the risk of rehospitalization. Therefore we sought to investigate the continuity and effectiveness of outpatient care after inpatient discharge and its effect on rehospitalization of patients with schizophrenia.

Methods Data were extracted from National Health Insurance Claim Database covering the period from 2007 through 2010 . We identified 10,246 patients aged 18 years or older who were admitted in psychiatric facilities with the diagnosis of schizophrenia between January 1 and December 31 in 2007. The number of outpatient visits within 60 days after discharge from index admission was defined as the indicator for the continuous care and rehospitalization was inspected during the following 36-month period. Cox's proportional hazard model was used to examine the factors affecting the risk of rehospitalization including the number of outpatient visits, age, sex, comorbidities, antipsychotics, and characteristics of medical institution.

Results We found that $12.7 \%(n=1,327)$ of the patients visited psychiatric outpatient department once within 60 days after hospital discharge, $34.8 \%(n=3,626)$ twice, and $27.8 \%(n=2,900)$ more than three times. Patients taking atypical antipsychotics showed higher proportion in 2 or more outpatient visits, whereas patients taking typical antipsychotics showed higher proportion in one or no outpatient visits. Cox hazard ratios of rehospitalization for the factor of 3 or more outpatient visits referenced to that of no follow-up visit were $0.567(0.428-0.750,95 \%$ confidence interval) within 90 days, $0.673(0.574-0.789)$ within 180 days, $0.800(0.713-0.898)$ within a year, $0.906(0.824-0.997)$ within 2 years, and $0.993(0.910-1.084)$ within 3 years.

Conclusion Although continuous outpatient treatment is important for relapse prevention, patients with schizophrenia showed a low rate of outpatient visit as $62.6 \%$ of total patients in 2 or more visits within 60 days after discharge. Lack of follow-up treatment might lead to increase psychotic symptoms and raised risk of relapse and rehospitalization. Our data suggest that the number of outpatient visits within 60 days after discharge in patients with schizophrenia is an important indicator of rehospitalization within a year. Therefore, further efforts to examine factors affecting failure of outpatient follow-up after discharge are warranted.

Psychiatry Investig 2015;12(4):425-433

Key Words Schizophrenia, Health insurance, Rehospitalization, Outpatient visits.

\section{INTRODUCTION}

Schizophrenia is a chronic, severe, and disabling disorder involving physical, social and economic aspects. Globally, it shows approximately $1 \%$ of lifetime prevalence. ${ }^{1}$ The outcome of schizophrenia is known to be diverse and heterogenic. Among the patients receiving standard treatment, approximately $20-40 \%$ experienced recurrence within a year, $60 \%$

\footnotetext{
Received: July 16, 2014 Revised: January 17, 2015 Accepted: February 3, 2015 Available online: April 15, 2015

$\triangle$ Correspondence: Jong-Woo Paik, MD, PhD

Department of Neuropsychiatry, College of Medicine, Kyung Hee University, 23 Kyungheedae-ro, Dongdaemun-gu, Seoul 02447, Republic of Korea

Tel: +82-2-958-8419, Fax: +82-2-957-1997, E-mail: paikjw@khu.ac.kr

*These authors equally contributed.

(c) This is an Open Access article distributed under the terms of the Creative Commons Attribution Non-Commercial License (http://creativecommons.org/licenses/by-nc/3.0) which permits unrestricted non-commercial use, distribution, and reproduction in any medium, provided the original work is properly cited.
} 
within two years and $82 \%$ within 5 years. ${ }^{2-7}$ Medical care cost of such relapsed patients is about twice as much as that of the patients without recurrence, $61 \%$ of which is related to hospitalization. ${ }^{1,8}$ Therefore, it is very important to identify the factors affecting recurrence and rehospitalization.

Variables related to recurrence or rehospitalization have been studied, including male sex, old age, single or divorced marital status, early occurrence, history of multiple hospitalizations, severe symptoms during hospitalization and after discharge, unemployment, level of adaptation before occurrence, accompaniment of material abuse, and reduced compliance after discharge. ${ }^{7,9-15}$ In particular, low drug compliance is the most common factor contributing to recurrence and rehospitalization of patients with schizophrenia, and is strongly related to negative outcomes such as aggravated symptoms, social withdrawal. ${ }^{15-17}$

High discontinuation rate of antipsychotics in patients with schizophrenia has been documented in previous studies. In the Clinical Antipsychotic Trials of Intervention Effectiveness (CATIE), 74\% of chronic schizophrenia patients discontinued their medication within 18 months, ${ }^{18}$ and in the European First Episode Schizophrenia Trial (EUFEST), 42\% incipient schizophrenia patients discontinued within 12 months. ${ }^{19}$ Apparently, the discontinuing medication increases the risk of recurrence by 5 times. ${ }^{7}$ Thus, to prevent recurrence and rehospitalization and improve their social adaptation, improving adherence of antipsychotic medication is essential, and a regular and constant outpatient care may foster such adherence. ${ }^{20}$ Although the critical importance of regular outpatient treatment is being recognized, naturalistic studies found that 33$44 \%$ patients quit treatment within the first 6 months and 59\% within the first year. ${ }^{21-27}$ Medication non-adherence was more common among patients with than without recurrence $(70 \%$ vs. $25 \%, \mathrm{p}=0.001)$. Thus, discontinuing medication due to drop out from outpatient care is a major risk factor of rehospitalization of patients with schizophrenia. ${ }^{28-30}$

However, there is a paucity of research on the association between outpatient care and rehospitalization. Former studies focused on patient's characteristics or index hospitalizationrelated factors. ${ }^{11,31-34}$ Only a handful of studies have shown that regular outpatient visit after discharge was related to a low rate of rehospitalization and high drug compliance. ${ }^{29,35,36}$ As was shown in the report by Tiihonen et al., the group taking antipsychotics showed a significantly lower rehospitalization rate, though 1,496 out of 2,588 patients (57.8\%) were rehospitalized during the two-year follow-up observation period. ${ }^{37}$ Thus, to reduce rehospitalization rate, maintenance of regular medication through outpatient care is of critical importance.

Early rehospitalization within 30 days after discharge may be associated with short hospitalization in the last treatment, symptoms at the time of recurrence, effects of treatment during hospitalization, and discharge plan of inpatient. However, it fails to reflect the intervention effects of outpatient treatment after discharge. ${ }^{10,34,36,38}$ Accordingly, this study focused on outpatient visits after discharge and we extended the observation period to 60 days to identify the relationship between outpatient visits and rehospitalization.

In this study, we hypothesized that the number of outpatient visits within 60 days after discharge was inversely related to the risk of rehospitalization. Therefore, we compared various factors among subgroups based on the number of outpatient visits within 60 days after discharge and sought to elucidate the effects of outpatient visits on the rehospitalization rate within three years using National Health Insurance Claim Database (NHICD).

\section{METHODS}

\section{Data source}

We performed a population-based retrospective cohort study, using data extracted from NHICD. Korea has a national health insurance system and the medical cost claimed by medical institutions is reviewed by Health Insurance Review \& Assessment Service. NHICD encompasses a wide range of clinical information including general characteristics of patients, diagnosis, medical treatment history and medical institution characteristics.

This study was performed as a part of the development OECD Healthcare quality indicators in 2009 supported by Ministry of Health and Welfare in Korea.

\section{Study population}

The subjects were patients with schizophrenia aged over 18 years and admitted between January 1 and December 31 in the year of 2007. For the definition of patients with schizophrenia, we included patients whose principal or first secondary diagnosis was either schizophrenia (F20.0-F20.9) or schizoaffective disorders (F25.0, F25.1, F25.2, F25.8, F25.9) based on the 10th revision of International Statistical Classification of Diseases and Related Health Problems (ICD-10). ${ }^{39}$ Patients who were subject to medical aid were excluded because details on prescriptions were not available in NHICD. Among 19,570 patients who met our primary selection criteria, those who were rehospitalized, transferred to other hospital, or expired within 60 days after discharge were excluded because they have not been benefited from outpatient treatment. Finally, 10,426 patients taking antipsychotics during or after the hospitalization were included 3-year follow-up observation. 


\section{Variables}

\section{Outpatient visit and rehopitalization}

In this study, the correlation between outpatient visits after discharge and recurrence was analyzed. Based on the number of outpatient visits within 60 days after discharge, patients were categorized into four groups: never, once, twice, and three times or more. We defined rehospitalization as the event for survival analysis and regarded it as a result from recurrence of schizophrenia. Rehospitalization was checked for three years starting from post-discharge 61st day.

\section{Other explanatory variables}

The medical institutions of the index hospitalization were classified into general hospital, hospital and private clinic according to the types of facility, and into metropolitan city, small urban and rural district according to the location. Comorbidities such as hypertension and diabetes and past hospitalization history, length of stay (LOS) at the index admission and use of typical or atypical antipsychotics were selected as covariates. Use of atypical antipsychotics was defined as any use of it for any length of time during the observation period. We also examined comorbidities including depression (F32. $\mathrm{x}, \mathrm{F} 33 . \mathrm{x}, \mathrm{F} 341$, and F412), anxiety disorder(F40.x-F43.x), hypertension(I10.x-I15.x), and diabetes (E10.x-E14.x). Past hospitalization history was defined as any psychiatric within a year before the index hospitalization in 2007.

\section{Statistical analysis}

ANOVA with tukey's multiple comparison for continuous variables and Cochrane-Amitage's linear trend test or ChiSquare test for categorical variables in the analysis of groups based on the number of outpatient visits. Using Kaplan-Meier method, we carried out rehospitalization-free survival analysis and compared the survival curves of the four groups. To analyze the risk factors for rehospitalization, we used timedependent Cox's proportional hazard model with covariates, including age, gender, LOS, comorbidities, drug prescription and medical institution characteristics. SAS 9.13 (SAS Institute, Cary, NC, USA) was used for statistical analysis, and the significance level for all the tests was 0.05 .

\section{RESULTS}

\section{General characteristics of discharged schizophrenia patients}

We included total 10,426 patients, among which $53.1 \%$ were female $(n=5,531)$ and $47.0 \%$ male $(n=4,895)$. The mean age of patients was 39.5 years. Past hospitalization was present in $27 \%$, and use of atypical antipsychotics at the time of discharge was found in $90.4 \%$ of the patients, showing a high atypical antipsychotics prescription rate. The prevalences of hypertension and diabetes were $6.8 \%$ and $5.5 \%$, respectively. Those of depression and anxiety disorder were $14.7 \%$, and $11.3 \%$, respectively. Majority of patients (87.9\%) were hospitalized in general hospital or hospital, and a half of the patients (49\%) visited medical institutions located in large cities (Table 1).

\section{General characteristics according to the number of outpatient visits after discharge}

A quarter of patients $(\mathrm{n}=2,573 ; 24.7 \%)$ never had outpatient visit within 60 days after discharge. Those who had one outpatient visit were $12.7 \%(\mathrm{n}=1,327)$, two visits $34.8 \%(\mathrm{n}=3,626)$, more than three visits $27.8 \%(\mathrm{n}=2,900)$. Among the patients over 65 years of age, those who never had outpatient visit after discharge were $61.5 \%$, while those with more than three visits $8.3 \%$. On the other hand, among patients between 18 and 44 years of age, $30.4 \%$ had more than three outpatient visits. Female patients showed a slightly higher number of visits than male although the difference was statistically insignificant.

Patients with a longer period of hospitalization showed more outpatient visits and those with an experience of prior hospitalization showed a higher rate of outpatient visits. Patients who had depression or anxiety disorder had more outpatient visits, but there was no difference in the number of outpatient visits between patients with and without hypertension or diabetes.

Although one outpatient visit rate of patients who had typical antipsychotics was higher (13.4\%) than those who had atypical antipsychotics (12.7\%), patients who had atypical antipsychotics showed a higher outpatient visit rate after discharge. Proportions of patients with 2 and 3 or more outpatient visits were higher in patients taking atypical antipsychotics (27.3\% and $25.4 \%$, respectively), whereas those of one or no outpatient visits was higher in patients taking typical antipsychotics (12.7\% and 23.7, respectively).

According to medical institution type, patients hospitalized in general hospitals or hospitals showed higher proportion in one and two outpatient visits than those hospitalized in private clinic but the proportion in three or more visits were highest in private clinic (49.6\%). When medical institutions were located in rural district, the patients showed a lower outpatient visit rate compared to those of the institutions in city area (metropolitan city or small urban).

\section{Multivariate analysis between the number of outpatient visits and rehospitalization}

We analyzed the association between the number of outpatient visits within 60 days after discharge and rehospitalization within 90 days, 180 days, 1 year, 2 years and 3 years after 
Table 1. General characteristics by the number of outpatient visits within 60 days after discharge

\begin{tabular}{|c|c|c|c|c|c|c|c|}
\hline \multirow{2}{*}{ Variable } & \multirow{2}{*}{ Category } & \multirow{2}{*}{ Total } & \multicolumn{4}{|c|}{ Number of outpatient visit } & \multirow{2}{*}{ p-value* } \\
\hline & & & 0 & 1 & 2 & $\geq 3$ & \\
\hline Total & & $10,426(100)$ & $2,573(24.7)$ & $1,327(12.7)$ & $3,626(34.8)$ & $2,900(27.8)$ & \\
\hline Length of stay & & $44.9 \pm 33.6$ & $40.3 \pm 34.3$ & $44.8 \pm 34.6$ & $46.7 \pm 33.5$ & $46.8 \pm 32.3$ & $<0.0001^{\dagger}$ \\
\hline \multirow[t]{4}{*}{ Age } & & $39.5 \pm 13.2$ & $44.0 \pm 16.2$ & $40.1 \pm 12.7$ & $38.1 \pm 11.7$ & $36.8 \pm 10.9$ & $<0.0001^{\dagger}$ \\
\hline & $18-44$ & $7,300(70.0)$ & $1,477(20.2)$ & $909(12.5)$ & $2,693(36.9)$ & $2,221(30.4)$ & $<0.0001^{\ddagger}$ \\
\hline & $45-64$ & $2,537(24.3)$ & $734(28.9)$ & $355(14.0)$ & $818(32.2)$ & $630(24.8)$ & \\
\hline & $\geq 65$ & $589(5.7)$ & $362(61.5)$ & $63(10.7)$ & $115(19.5)$ & $49(8.3)$ & \\
\hline \multirow[t]{2}{*}{ Sex } & Male & $4,895(47.0)$ & $1,303(26.6)$ & $629(12.9)$ & $1,679(34.3)$ & $1,284(26.2)$ & $<0.0001$ \\
\hline & Female & $5,531(53.1)$ & $1,270(23.0)$ & $698(12.6)$ & $1,947(35.2)$ & $1,616(29.2)$ & \\
\hline \multirow[t]{2}{*}{ Hypertension } & No & $9,719(93.2)$ & $2,386(24.6)$ & $1,239(12.8)$ & $3,381(34.8)$ & $2,713(27.9)$ & 0.6770 \\
\hline & Yes & 707 (6.8) & $187(26.5)$ & $88(12.5)$ & $245(34.7)$ & $187(26.5)$ & \\
\hline \multirow[t]{2}{*}{ Diabetes } & No & $9,857(94.5)$ & $2,454(24.9)$ & $1,238(12.6)$ & $3,423(34.7)$ & $2,742(27.8)$ & 0.0548 \\
\hline & Yes & $569(5.5)$ & $119(20.9)$ & $89(15.6)$ & $203(35.7)$ & $158(27.8)$ & \\
\hline \multirow[t]{2}{*}{ Depression } & No & $8,899(85.4)$ & $2,259(25.4)$ & $1,101(12.4)$ & $3,093(34.8)$ & $2,446(27.5)$ & 0.0001 \\
\hline & Yes & $1,527(14.7)$ & $314(20.6)$ & $226(14.8)$ & $533(34.9)$ & $454(29.7)$ & \\
\hline \multirow[t]{2}{*}{ Anxiety disorder } & No & $9,245(88.7)$ & $2,318(25.1)$ & $1,159(12.5)$ & $3,220(34.8)$ & $2,548(27.6)$ & 0.0239 \\
\hline & Yes & $1,181(11.3)$ & $255(21.6)$ & $168(14.2)$ & $406(34.4)$ & $352(29.8)$ & \\
\hline \multirow[t]{2}{*}{ Previous admission } & No & $7,607(73.0)$ & $1,984(26.1)$ & $928(12.2)$ & $2,555(33.6)$ & $2,140(28.1)$ & $<0.0001$ \\
\hline & Yes & $2,819(27.0)$ & $589(20.9)$ & $399(14.2)$ & $1,071(38.0)$ & $760(27.0)$ & \\
\hline \multirow[t]{2}{*}{ Antipsychotics } & Typical & $1,006(9.7)$ & 341 (33.9) & $135(13.4)$ & $275(27.3)$ & $255(25.4)$ & $<0.0001$ \\
\hline & Atypical & $9,420(90.4)$ & $2,232(23.7)$ & $1,192(12.7)$ & $3,351(35.6)$ & $2,645(28.1)$ & \\
\hline \multirow[t]{3}{*}{ Hospital type } & General hospital & $3,762(36.1)$ & $775(20.6)$ & $420(11.2)$ & $1,450(38.5)$ & $1,117(29.7)$ & $<0.0001^{\ddagger}$ \\
\hline & Hospital & $5,402(51.8)$ & $1,482(27.4)$ & $801(14.8)$ & $1,962(36.3)$ & $1,157(21.4)$ & \\
\hline & Primary clinic & $1,262(12.1)$ & $316(25.0)$ & $106(8.4)$ & $214(17.0)$ & $626(49.6)$ & \\
\hline \multirow[t]{3}{*}{ Region } & Metropolitan city & $5,105(49.0)$ & $1,137(22.3)$ & $570(11.2)$ & $1,798(35.2)$ & $1,600(31.3)$ & $<0.0001^{\ddagger}$ \\
\hline & Small urban & $3,512(33.7)$ & $859(24.5)$ & $421(12.0)$ & $1,215(34.6)$ & $1,017(29.0)$ & \\
\hline & Rural district & $1,809(17.4)$ & $577(31.9)$ & $336(18.6)$ & $613(33.9)$ & $283(15.6)$ & \\
\hline
\end{tabular}

${ }^{*} \mathrm{p}$-values are calculated by Cochrane-Armitage’s linear trend test, and others specified, ${ }^{\dagger} \mathrm{p}$-values are calculated by ANOVA, ${ }^{\ddagger} \mathrm{p}$-values are calculated by chi-square test. ANOVA: analysis of variance

discharge. The risk of rehospitalization of patients who had 3 or more outpatient visits relative to that of counterpart without outpatient visit within 90 days was $0.567(0.428-0.750$, $95 \%$ confidence interval), within 180 days was 0.673 (0.574$0.789)$, within a year was $0.800(0.713-0.898)$, within 2 years 0.906 (0.824-0.997), which had a trend level significance and within 3 years $0.993(0.910-1.084)$ (Table 2). Kaplan-Meier analysis of rehospitalization-free survival in subgroups according to the number of outpatient visits showed that the difference in rehospitalization-free survival between subgroups was reduced after a year (Figure 1).

Length of inpatient stay, which was selected as proxy variable of severity of patients, did not have a significant association with risk of rehospitalization, and the risk of rehospitalization became lower with age. Patients with comorbidities such as hypertension, diabetes, depression and anxiety disor- der showed a higher risk of rehospitalization and those taking atypical antipsychotics had a lower risk of rehospitalization. Additionally, patients hospitalized in hospital or private clinic showed a higher rehospitalization risk than those hospitalized in general hospital. There was no significant difference in the risk of rehospitalization among the types of the area where the psychiatric institution is located in.

\section{DISCUSSION}

This study analyzed the association between outpatient visit and rehospitalization in patients with schizophrenia hospitalized in 2007. We could identify the association between outpatient visits and rehospitalization by performing a threeyear follow-up observation. It was confirmed that more outpatient visits within 60 days after discharge could lower 
SY Lee et al.

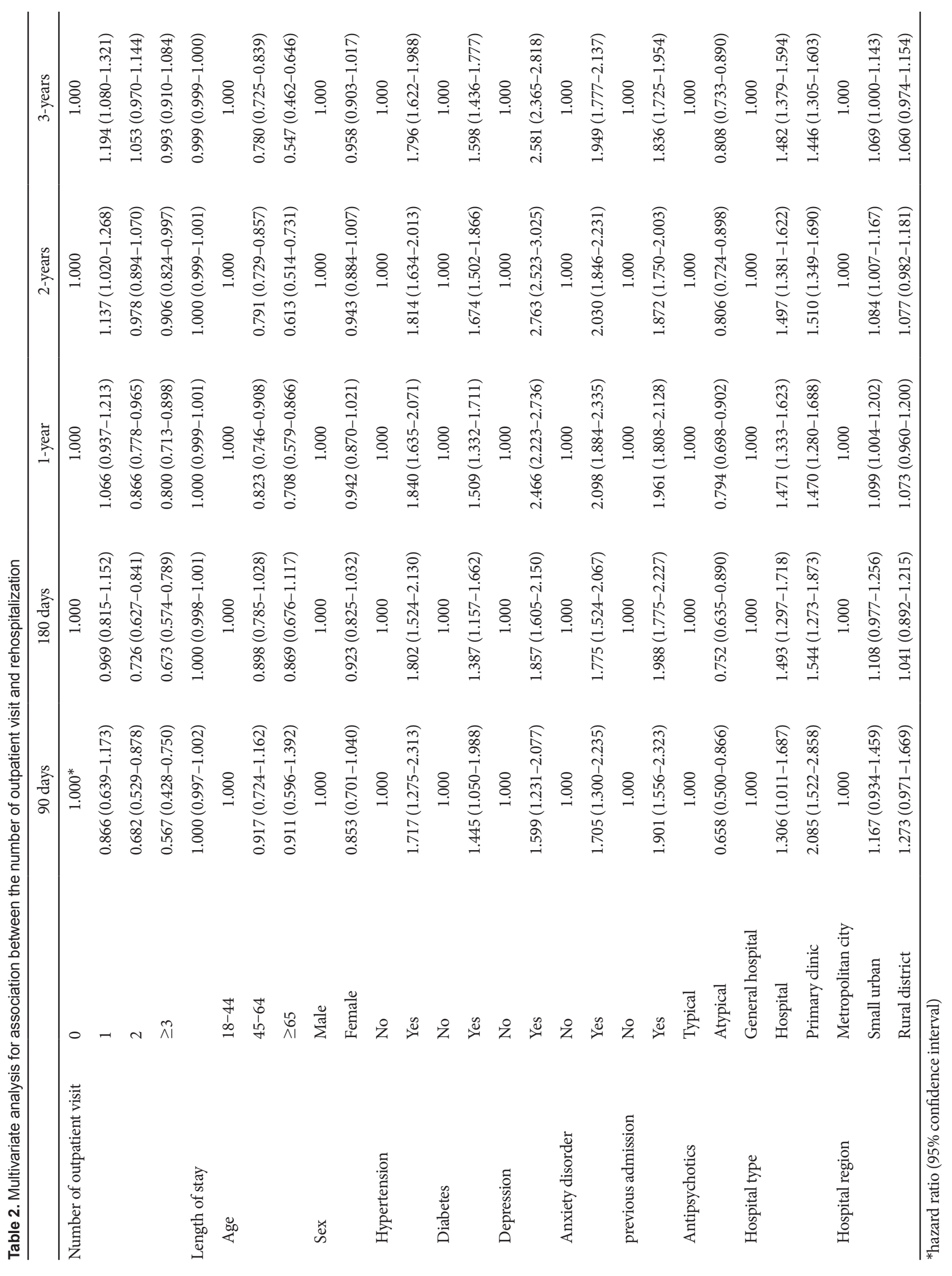




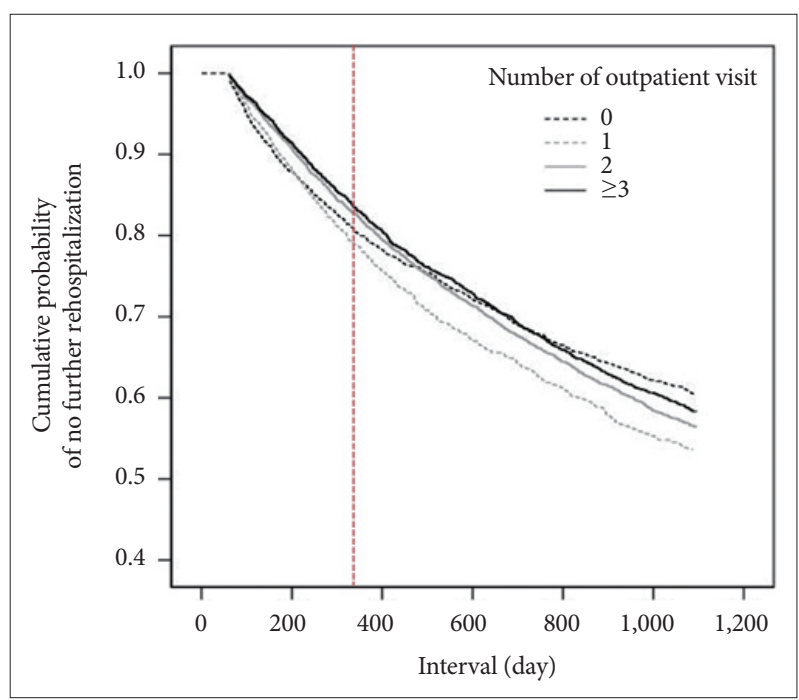

Figure 1. Cumulative probability of no further rehospitalization rate according to the number of outpatient visits on a Kaplan-Meier Curve.

the risk of rehospitalization within one year. Thus, the number of outpatient visits after discharge turned out to be a very important indicator of rehospitalization in maintenance treatment of schizophrenia. Some previous studies have emphasized the importance of outpatient visits after discharge. Lin et al. showed that Taiwanese patients with at least one outpatient visit within 60 days after discharge have a reduced risk of rehospitalization. ${ }^{38}$ Nelson et al. reported that patients with no outpatient visit after discharge have twice the risk of rehospitalization within a year, ${ }^{36}$ and Grinshpoon et al. ${ }^{40}$ reported that psychiatric patients with outpatient visits showed a significantly lower rehospitalization rate within 6 months than those without outpatient visits. Interestingly, we also found that the effects of outpatient visits were lost after a year. It is plausible that the predictability might have been weakened over time, because a relatively short period was investigated as an index period for post-discharge outpatient visits. Also, various factors such as use of community service, life events, or wax-and-wane nature of schizophrenia per se, might confound the association between the outpatient visits and rehospitalization in a longer period. To decide the index period of post-discharge visit for our study, it was inevitable to trade off representing ability against confounding effects. If the index period is too short it may not represent the tendency of outpatient visits, but if it is too long, the odds of being confounded by other factors might grow higher. The index period to " 2 months after discharge" has been used in prior study as well. ${ }^{38}$

These results suggest that not only inpatient treatment but also outpatient treatment is important. It has been shown that the compliance of outpatient appointment is higher when both the inpatient and outpatient care was provided by the same physician. ${ }^{41}$ Additionally, the first outpatient visit rate of the patients increases when there is a consultation between the inpatient doctor and outpatient doctor regarding the discharge plan during the hospitalization. ${ }^{42}$ Consequently, in order to minimize recurrence and rehospitalization, the establishment of post-discharge outpatient appointments seems to be critical.

The number of patients who failed to have outpatient visits within 60 days after discharge were 2,573 (24.7\%). The overall number of patients rehospitalized was 411 (3.94\%) within 90 days after discharge, 1278 (12.26\%) within 180 days, 2,492 (23.90\%) within a year, 3,712 (35.60\%) within two years, and $4,473(42.90 \%)$ within three years. Rehospitalization rate is similar to previous study, ${ }^{33}$ although it was higher than that of incipient schizophrenia. ${ }^{15}$ We found that among the comorbidities, presence of depression increased the number of outpatient visits within 60 days after discharge. However, all the comorbidities including depression increased the risk of rehospitalization as well. Taken together, depression can increase outpatient visit and rehospitalization at the same time which is inherently inconsistent with our main result. Positive and negative symptoms of schizophrenia have been shown to be associated with depression and anxiety which may lower the satisfaction of treatment and quality of life in patients with schizophrenia. ${ }^{43-46}$ Especially, depression in the first hospitalization reduces drug compliance and increases early recurrence and hospitalization. ${ }^{21,33,47}$ Therefore, it is conceivable that the increased outpatient visit in patients with depression should not be interpreted as a good compliance to maintenance treatment. Rather depression per se and/or negative symptoms of schizophrenia increases the necessity of outpatient treatment and the risk of rehospitalization. In this study, depression was present in $14.7 \%(n=27)$ of patients with schizophrenia, which is lower than the prevalence of depression in general population (25\%). ${ }^{48,49}$ Lower prevalence might be resulted from the inexactness of secondary diagnosis in NHICD, and partially from difficulty to differentiate depression from negative symptoms of schizophrenia. Hence, diagnosis of comorbid depression in schizophrenia is challenging but worthy of clinical attention to evaluate the risk of rehospitalization.

Age and sex were found to have a statistically significant association with the increased outpatient visits. Males showed fewer visits than females, which is consistent with the previous study result showing a lower treatment maintenance rate in men..$^{50}$ On the other hand, it is also reported that there was no significant difference between sexes. ${ }^{20,51}$ As to the rehospialization risk, we found that female sex and older age are protective factors against rehospitalization. This result is consis- 
tent with previous studies. ${ }^{29,52}$ Green et al. reported that rehospitalization is more frequent in the patients under the age of 40 years. ${ }^{29}$ There are controversy about the effect of sex on rehospitalization rate. ${ }^{28,34}$

Pharmacotherapy is one of the critical factor in the treatment of schizophrenia. In this study, the group taking atypical antipsychotics showed more outpatient visits and a lower risk of rehospitalization than the group taking typical antipsychotics. It is known that the group taking atypical antipsychotics has a lower treatment discontinuation rate, ${ }^{16,53}$ higher drug compliance, ${ }^{53-56}$ and lower rehospitalization rate. ${ }^{53}$ Higher medication adherence with taking atypical antipsychotics might be due to less side effects like extrapyramidal symptoms and tardive dyskinesia. ${ }^{57-62}$ However, some reports did not show the difference in drug compliance between typical and atypical antipsychotics. ${ }^{63,64}$ Olfson et al. ${ }^{63}$ proposed that the risk factors lowering drug compliance of discharged patients with schizophrenia, including past history of drug non-compliance, recent drug use, status that patients could not recognize their symptoms, weak relationship with staffs during the hospitalization, and the refusal of family members to intervene the patients' hospitalization. Eventually patients with low drug compliance could be easily dropped out although they had some outpatient visits.

We also found the number of outpatient visits is different according to the type and location of medical institutions. Primary clinic and metropolitan city showed relatively higher outpatient visit rate. It has been reported that outpatient treatment rate was higher in smaller hospitals and in the area with a higher ratio of psychiatrists per capita. ${ }^{65}$ Our results are consistent with previous report in that metropolitan city should have better accessibility to psychiatrists due to the higher ratio of psychiatrists per capita than rural area. From the perspective of the type of medical institutions, hospitals and primary clinics were consistently found to have higher rehospitalization risk than general hospitals. Considering the general tendencies that patients in acute phase or with good supporting system in a higher social and economic class tend to be hospitalized in general hospitals, the difference in rehospitalization rate may be resulted from the difference in patient group rather than treatment quality.

We also analyzed past hospitalization history and LOS as potential factors affecting outpatient visits and rehospitlization. We report that past hospitalization history increased the risk of rehospitalization, as similar findings have been reported. ${ }^{10,33,34,66}$ Although our data showed association between a longer LOS and more outpatient visits, it does not change the rehospitalization risk. In contrast, some previous studies reported that shorter LOS was related with vulnerability to recurrence, ${ }^{10,28}$ although there are some equivocal results as well. ${ }^{11,24,65}$ Korea has a single government-operated health insurance system. In particular, an enormous amount of NHICD has been accumulated as $99.9 \%$ of claims have been made via computerized network since $2007 .{ }^{67}$ NHICD the source of data for our study has strength in terms of representativeness, objectiveness and cost effectiveness. On the other hand, there is a possibility that the validity of diagnoses might be undermined by simple coding inaccuracy. However, in spite of general weak point of NHICD, the diagnosis of schizophrenia in our study should be more accurate than those of other diseases for several reasons. First, National Health Insurance Corporation requests careful diagnosis of the diseases under the application of "special benefit computation", including schizophrenia, Second, the diagnosis of schizophrenia is regarded as more serious because of the worries of potential social stigma. Third, we limited the subjects to those hospitalized in psychiatric institutions.

In the past, there were studies regarding outpatient visits after discharge in Korea but they were based on clinical studies. Therefore, the patients were not representative of the whole population and the number of subjects was smaller, because they were performed in a single medical institution. ${ }^{51}$ There have been some researches using national data, such as National Hospital Discharge Register in Finland from which mortality of schizophrenia was traced and correlation of antidepressant with suicidal risk and suicidal attempts was studied. ${ }^{68,69}$ As such, NHICD included data of all the patients diagnosed as a certain disease in all medical institutions. Therefore, generalizability and representativeness are the biggest strength of this study in that the cases visiting multiple institutions after discharge could be counted in outpatient visit compliance based on NHICD.

\section{Limitations}

1) Diagnosis in NHICD can be less accurate than the diagnosis through face-to-face structured interview. 2) Clinical information such as duration of untreated psychosis, intensity of symptoms and drug prescription during the hospitalization, and the use of community psychiatric service could not be considered in our study. Medical record review might enable in-depth analysis in the future. As this is a retrospective cohort study using NHICD, there are limitations in the method of study and characteristics of materials. Further study to overcome those limitation is warranted.

In this study, outpatient treatment within 60 days after discharge for patients with schizophrenia is an important indicator of rehospitalization within a year. We suggest that rehospitalization rate may be reduced if outpatient visits are maintained after discharge, especially within 60 days. Development of systematic and effective management program to increase 
outpatient treatment rate and drug compliance should have very important clinical implication.

\section{Acknowledgments}

This work was supported by a grant from the Kyung Hee University in 2008 (KHU-20071339).

\section{REFERENCES}

1. Hong J, Windmeijer F, Novick D, Haro JM, Brown J. The cost of relapse in patients with schizophrenia in the European SOHO (Schizophrenia Outpatient Health Outcomes) study. Prog Neuropsychopharmacol Biol Psychiatry 2009;33:835-841.

2. Davis JM. Overview: maintenance therapy in psychiatry: I. Schizophrenia. Am J Psychiatry 1975;132:1237-1245.

3. Hogarty GE. Prevention of relapse in chronic schizophrenic patients. J Clin Psychiatry 1993;54 Suppl:18-23.

4. Hogarty GE, Schooler NR, Ulrich R, Mussare F, Ferro P, Herron E. Fluphenazine and social therapy in the aftercare of schizophrenic patients. Relapse analyses of a two-year controlled study of fluphenazine decanoate and fluphenazine hydrochloride. Arch Gen Psychiatry 1979;36: 1283-1294.

5. Hogarty GE, Ulrich RF. The limitations of antipsychotic medication on schizophrenia relapse and adjustment and the contributions of psychosocial treatment. J Psychiatr Res 1998;32:243-250.

6. Schooler NR, Keith SJ, Severe JB, Matthews SM, Bellack AS, Glick ID, et al. Relapse and rehospitalization during maintenance treatment of schizophrenia. The effects of dose reduction and family treatment. Arch Gen Psychiatry 1997;54:453-463.

7. Robinson D, Woerner MG, Alvir JM, Bilder R, Goldman R, Geisler S, et al. Predictors of relapse following response from a first episode of schizophrenia or schizoaffective disorder. Arch Gen Psychiatry 1999; 56:241-247.

8. Chien IC, Chou YJ, Lin CH, Bih SH, Chang HJ, Chou P. Use of health care services and costs of psychiatric disorders among National Health Insurance enrollees in Taiwan. Psychiatr Serv 2004;55:1427-1430.

9. Eldon Taylor C, Lopiccolo CJ, Eisdorfer C, Clemence C. Best practices: reducing rehospitalization with telephonic targeted care management in a managed health care plan. Psychiatr Serv 2005;56:652-654.

10. Appleby L, Desai PN, Luchins DJ, Gibbons RD, Hedeker DR. Length of stay and recidivism in schizophrenia: a study of public psychiatric hospital patients. Am J Psychiatry 1993;150:72-76.

11. Appleby L, Luchins DJ, Desai PN, Gibbons RD, Janicak PG, Marks R. Length of inpatient stay and recidivism among patients with schizophrenia. Psychiatr Serv 1996;47:985-990.

12. Saarento O, Kastrup M, Lonnerberg O, Gostas G, Muus S, Sandlund M, et al. The Nordic Comparative Study on Sectorized Psychiatry: patients who use only psychiatric in-patient care in comprehensive community-based services--a 1-year follow-up study. Acta Psychiatr Scand 1998; 98:98-104

13. Dincin J, Wasmer D, Witheridge TF, Sobeck L, Cook J, Razzano L. Impact of assertive community treatment on the use of state hospital inpatient bed-days. Hosp Community Psychiatry 1993;44:833-838.

14. Pfeiffer SI, O'Malley DS, Shott S. Factors associated with the outcome of adults treated in psychiatric hospitals: a synthesis of findings. Psychiatr Serv 1996;47:263-269.

15. Ucok A, Polat A, Cakir S, Genc A. One year outcome in first episode schizophrenia. Predictors of relapse. Eur Arch Psychiatry Clin Neurosci 2006;256:37-43.

16. Jung SH, Kim WH, Choi HJ, Kang MH, Lee JS, Bae JN, et al. Factors affecting treatment discontinuation and treatment outcome in patients with schizophrenia in Korea: 10-year follow-up study. Psychiatry Investig 2011;8:22-29.

17. Novick D, Haro JM, Suarez D, Perez V, Dittmann RW, Haddad PM.
Predictors and clinical consequences of non-adherence with antipsychotic medication in the outpatient treatment of schizophrenia. Psychiatry Res 2010;176:109-113.

18. Lieberman JA, Stroup TS, McEvoy JP, Swartz MS, Rosenheck RA, Perkins DO, et al. Effectiveness of antipsychotic drugs in patients with chronic schizophrenia. N Engl J Med 2005;353:1209-1223.

19. Kahn RS, Fleischhacker WW, Boter H, Davidson M, Vergouwe Y, Keet IP, et al. Effectiveness of antipsychotic drugs in first-episode schizophrenia and schizophreniform disorder: an open randomised clinical trial. Lancet 2008;371:1085-1097.

20. Wang HR, Woo YS, Jung YE, Song HR, Jun TY, Bahk WM. Predictors of continuity of care after inpatient discharge of patients with schizophrenia: a retrospective chart review study in a university hospital. Korean J Psychopharmacol 2010;21:195-201.

21. Perkins DO, Gu H, Weiden PJ, McEvoy JP, Hamer RM, Lieberman JA, et al. Predictors of treatment discontinuation and medication nonadherence in patients recovering from a first episode of schizophrenia, schizophreniform disorder, or schizoaffective disorder: a randomized, double-blind, flexible-dose, multicenter study. J Clin Psychiatry 2008; 69:106-113.

22. Perkins DO, Johnson JL, Hamer RM, Zipursky RB, Keefe RS, Centorrhino F, et al. Predictors of antipsychotic medication adherence in patients recovering from a first psychotic episode. Schizophr Res 2006;83: 53-63.

23. Robinson DG, Woerner MG, Alvir JM, Bilder RM, Hinrichsen GA, Lieberman JA. Predictors of medication discontinuation by patients with first-episode schizophrenia and schizoaffective disorder. Schizophr Res 2002;57:209-219.

24. Coldham EL, Addington J, Addington D. Medication adherence of individuals with a first episode of psychosis. Acta Psychiatr Scand 2002; 106:286-290.

25. Verdoux H, Lengronne J, Liraud F, Gonzales B, Assens F, Abalan F, et al. Medication adherence in psychosis: predictors and impact on outcome. A 2-year follow-up of first-admitted subjects. Acta Psychiatr Scand 2000;102:203-210.

26. Mojtabai R, Lavelle J, Gibson PJ, Sohler NL, Craig TJ, Carlson GA, et al. Gaps in use of antipsychotics after discharge by first-admission patients with schizophrenia, 1989 to 1996. Psychiatr Serv 2002;53:337-339.

27. Mutsatsa SH, Joyce EM, Hutton SB, Webb E, Gibbins H, Paul S, et al. Clinical correlates of early medication adherence: West London first episode schizophrenia study. Acta Psychiatr Scand 2003;108:439-446.

28. Boden R, Brandt L, Kieler H, Andersen M, Reutfors J. Early non-adherence to medication and other risk factors for rehospitalization in schizophrenia and schizoaffective disorder. Schizophr Res 2011;133:36-41.

29. Green JH. Frequent rehospitalization and noncompliance with treatment. Hosp Community Psychiatry 1988;39:963-966.

30. Fenton WS, Blyler CR, Heinssen RK. Determinants of medication compliance in schizophrenia: empirical and clinical findings. Schizophr Bull 1997;23:637-651.

31. Lin HC, Tian WH, Chen CS, Liu TC, Tsai SY, Lee HC. The association between readmission rates and length of stay for schizophrenia: a 3-year population-based study. Schizophr Res 2006;83:211-214.

32. Lyons JS, O’Mahoney MT, Miller SI, Neme J, Kabat J, Miller F. Predicting readmission to the psychiatric hospital in a managed care environment: implications for quality indicators. Am J Psychiatry 1997;154: 337-340.

33. Olfson M, Mechanic D, Boyer CA, Hansell S, Walkup J, Weiden PJ. Assessing clinical predictions of early rehospitalization in schizophrenia. J Nerv Ment Dis 1999;187:721-729.

34. Swett C. Symptom severity and number of previous psychiatric admissions as predictors of readmission. Psychiatr Serv 1995;46:482-485.

35. Compton MT, Rudisch BE, Craw J, Thompson T, Owens DA. Predictors of missed first appointments at community mental health centers after psychiatric hospitalization. Psychiatr Serv 2006;57:531-537.

36. Nelson EA, Maruish ME, Axler JL. Effects of discharge planning and 
compliance with outpatient appointments on readmission rates. Psychiatr Serv 2000;51:885-889.

37. Tiihonen J, Haukka J, Taylor M, Haddad PM, Patel MX, Korhonen P. A nationwide cohort study of oral and depot antipsychotics after first hospitalization for schizophrenia. Am J Psychiatry 2011;168:603-609.

38. Lin HC, Lee HC. The association between timely outpatient visits and the likelihood of rehospitalization for schizophrenia patients. Am J Orthopsychiatry 2008;78:494-497.

39. World Health Organization. The ICD-10 Classification of Mental and Behavioral Disorders: Clinical Descriptions and Diagnostic Guidelines. Geneva: World Health Organization; 1992.

40. Grinshpoon A, Lerner Y, Hornik-Lurie T, Zilber N, Ponizovsky AM. Post-discharge contact with mental health clinics and psychiatric readmission: a 6-month follow-up study. Isr J Psychiatry Relat Sci 2011; 48:262-267.

41. Olfson M, Mechanic D, Boyer CA, Hansell S. Linking inpatients with schizophrenia to outpatient care. Psychiatr Serv 1998;49:911-917.

42. Boyer CA, McAlpine DD, Pottick KJ, Olfson M. Identifying risk factors and key strategies in linkage to outpatient psychiatric care. Am J Psychiatry 2000;157:1592-1598.

43. Norman RM, Malla AK, Cortese L, Diaz F. Aspects of dysphoria and symptoms of schizophrenia. Psychol Med 1998;28:1433-1441.

44. Norman RM, Malla AK. Dysphoric mood and symptomatology in schizophrenia. Psychol Med 1991;21:897-903.

45. Siris SG, Adan F, Cohen M, Mandeli J, Aronson A, Casey E. Postpsychotic depression and negative symptoms: an investigation of syndromal overlap. Am J Psychiatry 1988;145:1532-1537.

46. Huppert JD, Weiss KA, Lim R, Pratt S, Smith TE. Quality of life in schizophrenia: contributions of anxiety and depression. Schizophr Res 2001;51:171-180.

47. Geddes J, Mercer G, Frith CD, MacMillan F, Owens DG, Johnstone EC. Prediction of outcome following a first episode of schizophrenia. A follow-up study of Northwick Park first episode study subjects. Br J Psychiatry 1994;165:664-668.

48. Sands JR, Harrow M. Depression during the longitudinal course of schizophrenia. Schizophr Bull 1999;25:157-171.

49. McGlashan TH, Carpenter WT Jr. An investigation of the postpsychotic depressive syndrome. Am J Psychiatry 1976;133:14-19.

50. Kreyenbuhl J, Nossel IR, Dixon LB. Disengagement from mental health treatment among individuals with schizophrenia and strategies for facilitating connections to care: a review of the literature. Schizophr Bull 2009;35:696-703.

51. Park KG, Won SH, Kim SH, Kim HD, Kang BJ. The factors affecting follow-up treatment of schizophrenia after discharge. J Korean Soc Biol Ther Psychiatry 1998;4:210-222.

52. Doering S, Muller E, Kopcke W, Pietzcker A, Gaebel W, Linden M, et al. Predictors of relapse and rehospitalization in schizophrenia and schizoaffective disorder. Schizophr Bull 1998;24:87-98.

53. Al-Zakwani IS, Barron JJ, Bullano MF, Arcona S, Drury CJ, Cockerham TR. Analysis of healthcare utilization patterns and adherence in patients receiving typical and atypical antipsychotic medications. Curr
Med Res Opin 2003;19:619-626.

54. Dolder CR, Lacro JP, Dunn LB, Jeste DV. Antipsychotic medication adherence: is there a difference between typical and atypical agents? Am J Psychiatry 2002;159:103-108.

55. Gianfrancesco FD, Rajagopalan K, Sajatovic M, Wang RH. Treatment adherence among patients with bipolar or manic disorder taking atypical and typical antipsychotics. J Clin Psychiatry 2006;67:222-232.

56. Gianfrancesco FD, Rajagopalan K, Sajatovic M, Wang RH. Treatment adherence among patients with schizophrenia treated with atypical and typical antipsychotics. Psychiatry Res 2006;144:177-189.

57. Tollefson GD, Beasley CM Jr, Tamura RN, Tran PV, Potvin JH. Blind, controlled, long-term study of the comparative incidence of treatmentemergent tardive dyskinesia with olanzapine or haloperidol. Am J Psychiatry 1997;154:1248-1254.

58. Kane J, Honigfeld G, Singer J, Meltzer H. Clozapine for the treatmentresistant schizophrenic. A double-blind comparison with chlorpromazine. Arch Gen Psychiatry 1988;45:789-796.

59. Jeste DV, Rockwell E, Harris MJ, Lohr JB, Lacro J. Conventional vs. newer antipsychotics in elderly patients. Am J Geriatr Psychiatry 1999; 7:70-76.

60. Jeste DV, Lacro JP, Bailey A, Rockwell E, Harris MJ, Caligiuri MP. Lower incidence of tardive dyskinesia with risperidone compared with haloperidol in older patients. J Am Geriatr Soc 1999;47:716-719.

61. Small JG, Hirsch SR, Arvanitis LA, Miller BG, Link CG. Quetiapine in patients with schizophrenia. A high- and low-dose double-blind comparison with placebo. Seroquel Study Group. Arch Gen Psychiatry 1997; 54:549-557.

62. Marder SR, Meibach RC. Risperidone in the treatment of schizophrenia. Am J Psychiatry 1994;151:825-835.

63. Olfson M, Mechanic D, Hansell S, Boyer CA, Walkup J, Weiden PJ. Predicting medication noncompliance after hospital discharge among patients with schizophrenia. Psychiatr Serv 2000;51:216-222.

64. Cabeza IG, Amador MS, Lopez CA, Gonzalez de Chavez M. Subjective response to antipsychotics in schizophrenic patients: clinical implications and related factors. Schizophr Res 2000;41:349-355.

65. Olfson M, Marcus SC, Doshi JA. Continuity of care after inpatient discharge of patients with schizophrenia in the Medicaid program: a retrospective longitudinal cohort analysis. J Clin Psychiatry 2010;71:831-838.

66. Rosenblatt A, Mayer JE. The recidivism of mental patients: a review of past studies. Am J Orthopsychiatry 1974;44:697-706.

67. Health Insurance Review \& Assessment Service (HIRA). IT \& Other activities, Part III. Seoul, Korea: HIRA; 2011.

68. Tiihonen J, Lonnqvist J, Wahlbeck K, Klaukka T, Niskanen L, Tanskanen A, et al. 11-year follow-up of mortality in patients with schizophrenia: a population-based cohort study (FIN11 study). Lancet 2009; 374:620-627.

69. Tiihonen J, Lonnqvist J, Wahlbeck K, Klaukka T, Tanskanen A, Haukka J. Antidepressants and the risk of suicide, attempted suicide, and overall mortality in a nationwide cohort. Arch Gen Psychiatry 2006;63: 1358-1367. 